\title{
Correlation between Sequencing Results from Liquid Plasma and Dried Plasma Spot (DPS) for Determination of HIV Type 1 Non-B Subtypes
}

\author{
Erick Ntambwe Kamangu ${ }^{1,2 *}$, Adawaye Chatté ${ }^{3}$, Dolores Vaira ${ }^{4}$, Patrick de $\mathrm{Mol}^{5}$, \\ Georges Lelo Mvumbi', Richard Lunganza Kalala1, Marie-Pierre Hayette ${ }^{4,5}$
}

\footnotetext{
${ }^{1}$ Molecular Biology Unit, Department of Basic Sciences, Faculty of Medicine, University of Kinshasa (UNIKIN), Kinshasa, Democratic Republic of Congo (DRC)

${ }^{2}$ Research Group “Focus HIV/AIDS”, Kinshasa, Democratic Republic of Congo (DRC)

${ }^{3}$ University Institute of Science and Technology of Abéché, Abéché, Chad

${ }^{4}$ AIDS Reference Laboratory (ARL), Centre Hospitalier Universitaire-Université de Liège (CHU-Lg), Liège, Belgium ${ }^{5}$ Clinical Microbiology Laboratory, Centre Hospitalier Universitaire-Université de Liège (CHU-Lg), Liège, Belgium Email: *erick.kamangu@unikin.ac.cd
}

How to cite this paper: Kamangu, E.N., Chatté, A., Vaira, D., de Mol, P., Mvumbi, G.L., Kalala, R.L. and Hayette, M.-P. (2017) Correlation between Sequencing Results from Liquid Plasma and Dried Plasma Spot (DPS) for Determination of HIV Type 1 Non-B Subtypes. Open Access Library Journal, 4: e2922.

https://doi.org/10.4236/oalib.1102922

Received: December 22, 2016

Accepted: February 1, 2017

Published: February 4, 2017

Copyright $\odot 2017$ by authors and Open Access Library Inc.

This work is licensed under the Creative Commons Attribution International License (CC BY 4.0).

http://creativecommons.org/licenses/by/4.0/

\begin{abstract}
Background: The blotting paper is an alternative to the collection of blood in the tubes for analysis, especially in the field of Human Immunodeficiency Virus infection. This technique allows to easily send the collected samples to specialized laboratories while limiting the stresses of storage and transport. Objective: The objective of this study was to compare the results of sequencing performed on liquid plasma and Dried Plasma Spot (DPS) for the variants of HIV-1 non-B. Methodology: Fifty subjects diagnosed positive for HIV Type 1 using the Rapid Screening Tests voluntarily participated in this study. Two hundred microliters of plasma are deposited on blotting paper Whatman 903 and $500 \mu \mathrm{l}$ in a micro tube. RNA was extracted from $140 \mu \mathrm{l}$ of plasma fluid and from a piece of DPS of $5 \mathrm{~mm}$ of diameter using the QIAamp RNA Mini Kit QIAGEN ${ }^{\circledR}$. After extraction, the Viral Load (VL) was performed on each sample of liquid plasma. A Reverse Transcription PCR and Nested PCR were used to amplify the regions of interest on the Protease and Reverse Transcriptase for subsequent sequencing. Results: Protease and Reverse Transcriptase were amplified and sequenced respectively for $44(88 \%)$ and 48 (96\%) with the liquid plasma samples and $40(80 \%)$ and $45(90 \%)$ with the DPS. The results of Viral Loads were in the range of $2.5 \log _{10}$ and $6.5 \log _{10}$. The results of sequencing are comparable for plasma samples and DPS. The correlation coefficient $\left(R^{2}\right)$ between the two methods is good $\left(R^{2}=0.903, p<0.001\right)$. Conclusion: Liquid Plasma and Dried Plasma Spot give highly correlated results for sequencing strains of HIV type 1 non-B.
\end{abstract}




\section{Subject Areas}

HIV

\section{Keywords}

Sequencing, Liquid Plasma, Dried Plasma Spot, HIV-1 Non-B, Kinshasa

\section{Introduction}

Human Immunodeficiency Virus (HIV) is classified into 2 types (HIV-1 and HIV-2) which each one comprises different groups and subtypes [1]. Worldwide, the subtype C of HIV-1 group M dominates the epidemiology with nearly $70 \%$ of cases [2] [3]. Meanwhile, in sub-Saharan Africa, molecular epidemiology is dominated by subtypes A, C, G and various recombinant forms [1] [2] [3].

Used for more than 50 years, the blotted paper or Dried Blood Spot (DBS) is an alternative to the collection of blood in the tubes for analysis, especially in the field of HIV infection [4]. The DBS technique allows to easily send collected samples to specialized laboratories while limiting constraints due to storage and transport conditions. DBS can be crafted from any medium (blood, plasma, serum) in compliance with Good Laboratory standards and even routed by a local postal service [5].

To optimize the performance of the RNA extraction, the Dried Plasma Spot (DPS) was developed as an alternative to DBS [5] [6] [7] [8] [9]. With this variant, whole blood collected with anticoagulant is previously centrifuged and only the plasma is then deposited on the support; this allows to limit the presence of DNA and other contaminants in a sample where should be detected only viral RNA [5] [6] [7] [8] [9]. This technique is often used for the amplification of RNA for genotyping and Viral Load (VL) in resource-limited settings [5] [6] [7] [8] [9].

The objective of this study was to compare the results of sequencing performed on Liquid Plasma and DPS for HIV-1 non-B variants.

\section{Methodology}

\subsection{Study Population}

Fifty (50) subjects diagnosed positive for HIV Type 1 using the Rapid Screening Tests (RDTs) voluntarily participated in this study after signing consent. They were recruited from different centers in Kinshasa. The sampling was done from August 1st, 2013 to February 28th, 2014. HIV positive patients were confirmed in the Laboratory of Molecular Biology of the University of Kinshasa using a PCR technique previously described [10].

\subsection{Blood Samples}

Five milliliters $(5 \mathrm{ml})$ of blood were collected in a tube with EDTA anticoagulant 
from the vein of the elbow crease. The collected blood was centrifuged at $1000 \mathrm{~g}$ for 10 minutes at room temperature to obtain a clear separation into 3 phases (plasma, buffy coat and Cullot). A milliliter of plasma (supernatant) was transferred into a pre-labeled micro centrifuge tube. These samples were mixed to ensure homogeneity and then aliquoted into two tubes (A and B) of $500 \mu \mathrm{l}$ each. Two hundred microliters $(200 \mu \mathrm{l})$ of plasma from tube B was deposited on blotting paper Whatman 903 (DPS). The tube A and the DPS were sent to the AIDS Reference Laboratory (ARL) of the University Hospital of the University of Liège (CHU-ULg) in Belgium for sequencing.

\subsection{RNA Extraction, Amplification and Sequencing}

RNA was extracted ARL-CHU Liege from $140 \mu$ of liquid plasma and a piece of DPS of $5 \mathrm{~mm}$ of diameter using RNA Mini Kit QIAamp ${ }^{\circledR}$ Kit (QIAGEN) [11]. The DPS samples were incubated for 2 hours at $70^{\circ} \mathrm{C}$ to maximize the extraction results. RNA extracted samples were stored at $-80^{\circ} \mathrm{C}$ until use.

After extraction, the Viral Load (VL) was determined on each sample of liquid plasma using an in-house Quantitative PCR assay previously described for quantification of RNA [12].

A Reverse Transcription PCR (RT-PCR) and Nested PCR were used for amplifying the regions of interest on the Protease and Reverse Transcriptase (RT) for subsequent sequencing in conditions and temperature cycles previously described [13]. These PCR assay were used under the same conditions as described in the previous study [13].

The fragments obtained after amplification (Protease 500 base pairs and TR $800 \mathrm{bp}$ ) were sequenced by the Sanger sequencing method and purified by the ExoSAP-IT technique to eliminate the residual products of the PCR and sequenced by amplifying the purified fragment [13].

Pairing of the resulting fragments (sense and antisense) was done with the Vector NTI Advance ${ }^{\circledR} 11.5$ software (Invitrogen, Life Technologies) and compared with various databases to identify subtypes of HIV-1 [13] [14]

\subsection{Ethical Clearance}

The present study was approved by the university ethical comity and had received consent from the center where samplings were done. The supervising team had seen that no harm was done to the patients during blood collection.

\subsection{Statistics}

The Friedman test was used to analyze the differences of groups of variants.

\section{Results}

Fifty (50) patients infected with HIV Type 1 were selected for this study. Samples of DPS as well as plasma were sequenced successfully. Protease and Reverse Transcriptase were amplified and sequenced respectively for $44(88 \%)$ and 48 (96\%) with the liquid samples and 40 plasma (80\%) and 45 (90\%) with the DPS 
(Table 1).

\subsection{Viral Load and Subtyping}

The results of Viral Loads (VL) were in the range of $2.5 \log _{10}$ and $6.5 \log _{10}$. Ten patients $(20 \%)$ had a VL under $3.0 \log _{10}$ while $32(64 \%)$ had VL included between $3.0 \log _{10}$ and $6.0 \log _{10}$. Only 8 patients $(16 \%)$ had a VL greater than 6.0 $\log _{10}$.

From samples taken from the liquid plasma, subtype $\mathrm{A}$ is dominant with 12 cases (25\%); followed by CRF02_AG (14.6\%), C (10.4\%), G (10.4\%), K (8.3\%), D (8.3\%), $\mathrm{H}(6.25 \%)$ and $\mathrm{J}(6.25 \%)$ as presented in Table 2.

For samples collected on DPS, the subtype A is dominant with 10 cases (22.2\%); followed by CRF02_AG (17.8\%), C (8.9\%), D (8.9\%), G (8.9\%), H (6.7\%), J (6.7\%), K (6.7\%) and the CRF01_AE (6.7\%) (Table 2).

\subsection{Correlation of Results}

The results of sequencing are comparable for plasma samples and DPS. For the Protease, the results are comparable to the 40 amplified samples on DPS. At the Reverse Transcriptase, 2 samples (4.4\%) of the 45 amplified on DPS have presented different results; one subtype A sample from liquid plasma was presented as CRF02_AG from DPS, and another one subtype A sample from liquid plasma was presented as CRF01_AE from DPS. The correlation coefficient $\left(R^{2}\right)$ between the two methods is good $\left(\mathrm{R}^{2}=0.903, \mathrm{p}<0.001\right)$.

Table 1. Results of amplification.

\begin{tabular}{ccccc}
\hline \multirow{2}{*}{ Amplification } & \multicolumn{2}{c}{ Plasma liquid } & \multicolumn{2}{c}{ Dried Plasma Spot(DPS) } \\
\cline { 2 - 4 } & Protease & TR & Protease & TR \\
\hline Positive & $44(88 \%)$ & $48(96 \%)$ & $40(80 \%)$ & $45(90 \%)$ \\
Negative & $6(12 \%)$ & $2(4 \%)$ & $10(20 \%)$ & $5(10 \%)$ \\
\hline
\end{tabular}

Table 2. Frequencies of HIV type 1 subtypes.

\begin{tabular}{ccc}
\hline HIV-1 Subtypes & Frequency on Liquid Plasma $\mathbf{n}=\mathbf{4 8}(\%)$ & Frequency on DPS $\mathbf{n}=\mathbf{4 5}(\%)$ \\
\hline A & $12(25 \%)$ & $10(22.2 \%)$ \\
C & $5(10.4 \%)$ & $4(8.9 \%)$ \\
D & $4(8.3 \%)$ & $4(8.9 \%)$ \\
F & $1(2.1 \%)$ & $1(2.2 \%)$ \\
G & $5(10.4 \%)$ & $4(8.9 \%)$ \\
H & $3(6.25 \%)$ & $3(6.7 \%)$ \\
J & $3(6.25 \%)$ & $3(6.7 \%)$ \\
K & $4(8.3 \%)$ & $3(6.7 \%)$ \\
CRF01_AE & $2(4.2 \%)$ & $3(6.7 \%)$ \\
CRF02_AG & $7(14.6 \%)$ & $8(17.8 \%)$ \\
U & $2(4.2 \%)$ & $2(4.4 \%)$ \\
\hline
\end{tabular}




\section{Discussion}

The objective of this study was to compare the results of sequencing done from Liquid Plasma and Dried Plasma Spot (DPS) for samples of HIV-1 non-B. Fifty (50) HIV positive samples were collected, amplified and sequenced using various techniques of Molecular Biology.

Protease and Reverse Transcriptase were amplified and sequenced respectively for $44(88 \%)$ and 48 (96\%) samples with the Liquid plasma, while $40(80 \%)$ and 45 (90\%) with the DPS. This gives an average amplification higher than $80 \%$ for both. For DPS, all samples with a Viral Loads (VL) of less than $3.0 \log _{10}$ have not amplified for the Protease. These data confirm the literature on amplifications of DBS and DPS [5] [15] [16]. Various research groups have reported detection limit of amplification in the range of $3.0 \log _{10}$ and $3.33 \log _{10}$ with the use of blotting paper [5] [9] [15] [16]. With 20\% of the samples having a VL of less than 3.0 $\log _{10}$, the results obtained by sequencing in this study meet the standards and confirmed the literature.

In this study population, the subtype A is dominant with 12 cases (25\%); followed by CRF02_AG (14.6\%), C (10.4\%), G (10.4\%), K (8.3\%), D (8.3\%), H (6.25\%) and $\mathrm{J}(6.25 \%)$. This is consistent with what the literature presents in terms of the subtypes circulating in Kinshasa where the subtype A prevails [13].

The results of sequencing are comparable for plasma samples and DPS. For the Protease, the results are comparable to the 40 amplified samples. This may be justified because the sequence of the Protease, by its size ( \pm 124 nucleotides), is the least changing region to the HIV Type 1 genome [17], thus implying a uniformity of result of sequencing on plasma and DPS. For the Reverse Transcriptase, 2 samples (4.4\%) of the 45 amplified have presented different results; 1 sample of subtype A from liquid plasma was presented as CRF02_AG from DPS and one other subtype A sample from liquid plasma was presented as CRF01_AE from DPS. The correlation coefficient $\left(\mathrm{R}^{2}\right)$ between the two methods is good $\left(R^{2}=0.903, p<0.001\right)$. Nevertheless, the difference between subtype $A$ and CRF_01_AE and 02_AG is not large [18]. Several techniques have frequently assimilated and do not give a clear difference [18]. Hence, the results of Protease are most often considered as reverse transcriptase in the case of sequencing of HIV [18].

\section{Conclusion}

The Liquid Plasma and the Dried Plasma Spot (DPS) give highly correlated results for sequencing strains of HIV type 1 non-B. The Viral Loads below 3.00 $\log _{10}$ do not provide sequencing results on DPS. These results support the use of DPS for sequencing in countries with limited resources in cases of high viral load greater than $3.00 \log _{10}$.

\section{References}

[1] Robertson, D.L., Anderson, J.P., Bradac, J.A., Carr, J.K., Foley, B., Funkhouser, R.K., Gao, F., Hahn, B.H., Kalish, M.L., Kuiken, C., Learn, G.H., Leitner, T., McCutchan, 
F., Osmanov, S., Peeters, M., Pieniazek, D., Salminen, M., Sharp, P.M., Wolinsky, S. and Korber, B. (2000) HIV Type 1 Nomenclature Proposal. Science, 288, 55-56. https://doi.org/10.1126/science.288.5463.55d

[2] Papathanasopoulos, M.A., Hunt, G.M. and Tiemessen, C.T. (2003) Evolution and Diversity of HIV Type 1 in Africa: A Review. Virus Genes, 26, 151-163. https://doi.org/10.1023/A:1023435429841

[3] Hemelaar, J., Gouws, E., Ghys, P.D. and Osmanov, S. (2006) Global and Regional Distribution of HIV Type 1 Genetic Subtypes and Recombinants in 2004. AIDS, 20, W13-W23. https://doi.org/10.1097/01.aids.0000247564.73009.bc

[4] Mei, J.V., Alenxander, J.R., Adam, B.W. and Hannon, W.H. (2001) Use of Filter Paper for Collection and Analysis of Human Whole Blood Specimens. Journal of Nutrition, 131, 1631S-1636S.

[5] Chatté, A., Kamangu, E., Mahamat, M.A., Tchoumbou, B., Vaira, D. and Moutschen, M. (2013) Use of Dried Blood Spot to Improve the Diagnosis and Management of HIV in Resource-Limited Settings. World Journal of AIDS, 3, 251-256. https://doi.org/10.4236/wja.2013.33033

[6] Dachraoui, R., Brand, D., Brunet, S., Barin, F. and Plantier, J.C. (2008) RNA Amplification of the HIV-1 Pol and Env Regions on Dried Serum and Plasma Spots. HIV Medicine, 9, 557-561. https://doi.org/10.1111/j.1468-1293.2008.00604.x

[7] Hamers, R.L., Smit, P.W., Stevens, W., Schuurman, R. and Rinke de Wit, T.F. (2009) Dried Fluid Spots for HIV Type 1 Viral Load and Resistance Genotyping: A Systematic Review. Antiviral Therapy, 14, 619-629.

[8] Monleau, M., Montavon, C., Laurent, C., Segondy, M., Montes, B., Delaporte, E., Boillot, F. and Peeters, M. (2009) Evaluation of Different RNA Extraction Methods and Storage Conditions of Dried Plasma and Blood Spots for Human Immunodeficiency Virus Type 1 RNA Quantification and PCR Amplification for Drug Resistance Testing. Journal of Clinical Microbiology, 47, 1107-1118. https://doi.org/10.1128/JCM.02255-08

[9] Andreotti, M., Pirillo, M., Guidotti, G., Ceffa, S., Paturzo, G., Germano, P., Luhanga, R., Chimwaza, D., Mancini, M.G., Marazzi, M.C., Vella, S., Palombi, L. and Giuliano, M. (2010) Correlation between HIV-1 Viral Load Quantification in Plasma, Dried Blood Spots and Dried Plasma Spots Using the Roche COBAS TaqMan Assay. Journal of Clinical Virology, 47, 4-7. https://doi.org/10.1016/j.jcv.2009.11.006

[10] Kamangu, N.E., Mayemba, C., Mbikayi, S., Ndarabu, A., Kalala, L.R., Mvumbi, L.G. and Vaira, D. (2014) Implementation of a Classic Nested PCR DNA for HIV Diagnosis in Kinshasa. International Journal of Collaborative Research on Internal Medicine and Public Health, 6, 145-151.

[11] (2010) QIAGEN: QIAamp ${ }^{\circledR}$ RNA Mini and Blood Mini Handbook. 3rd Edition, 27-29.

[12] Kamangu, N.E., Chatte, A., Boreux, R., Kalala, L.R., Mvumbi, L.G., De Mol, P., Vaira, D. and Hayette, M.P. (2015) Implementation of an In-House Quantitative Real-Time PCR for Determination of HIV Viral Load in Kinshasa. Open Access Library Journal, 1: e0855. https://doi.org/10.4236/oalib.1100855

[13] Kamangu, N.E., Chatté, A., Susin, F., Boreux, R., Kalala, L.R., Mvumbi, L.G., De Mol, P., Vaira, D. and Hayette, M.P. (2015) Genetic Diversity and Antiretroviral Drug Resistance among Drug-Naïve HIV Type 1 Infected Patients attending Clinics in Kinshasa, Democratic Republic of Congo. Journal of HIV and AIDS, 1, 1-6.

[14] Tang, W.M., Liu, F.T. and Shafer, W.R. (2012) The HIVdb System for HIV-1 Genotypic Resistance Interpretation. Intervirology, 55, 98-101.

https://doi.org/10.1159/000331998 
[15] Hamers, R.L., Smit, P.W., Stevens, W., Schurman, R. and Rinke de Wit, T.F. (2009) Dried Fluid Spots for HIV Type 1 Viral Load and Resistance Genotyping: A Systematic Review. Antiviral Therapy, 14, 619-629.

[16] Masciotra, S., Garrido, C., Youngpairoj, A.S., Mc Nulty, A., Zahonero, N.Z., Corral, A., Heneine, W., de Mendoza, C. and Garcia-Lerma, J.G. (2007) High Concordance between HIV-1 Drug Resistance Genotypes Generated from Plasma and Dried Blood Spots in Antiretroviral-Experienced Patients. AIDS, 21, 2503-2511. https://doi.org/10.1097/QAD.0b013e3281c618db

[17] Fransen, K., Zhong, P., Beenhouwer, H., Carpels, G., Peeters, M., Louwagie, J., Jassens, W., Piot, P. and Van, G. (1994) Design and Evaluation of New, Highly Sensitive and Specific Primers for Polymerase Chain Reaction Detection of HIV-1 Infected Primary Lymphocytes. Molecular and Cellular Probes, 8, 317-322. https://doi.org/10.1006/mcpr.1994.1043

[18] Taylor, B.S., Sobieszczyk, M.E., McCutchan, F.E. and Hammer, S.M. (2008) The Challenge of HIV-1 Subtype Diversity. The New England Journal of Medicine, 358, 1590-1602. https://doi.org/10.1056/NEJMra0706737

Submit or recommend next manuscript to OALib Journal and we will provide best service for you:

- Publication frequency: Monthly

- 9 subject areas of science, technology and medicine

- Fair and rigorous peer-review system

- Fast publication process

- Article promotion in various social networking sites (LinkedIn, Facebook, Twitter, etc.)

- Maximum dissemination of your research work

Submit Your Paper Online: Click Here to Submit

Or Contact service@oalib.com 